LOS POLÍTICOS COMO

ENEMIGOS

\section{Gestión de los}

"external affairs" y

de las "government

relations"

\section{Jesús Timoteo Álvarez Fernández}

\section{Catedrático}

Facultad Ciencias de la Información. Universidad Complutense de Madrid. Avda. Complutense, s/n, 28040, Madrid (España) - Email: jesustimoteo@ccinf.ucm.es

\section{Resumen}

Desde 1980 se han desarrollado estrategias y programas de Asuntos Externos en modo que son ya formas convencionales de comunicación corporativa e institucional. Los más problemáticos y conflictivos de estos programas de Asuntos Externos son los de Relaciones con los Gobiernos, que aquí se analizan. Nos encontramos hoy con cuatro situaciones que se corresponden a las relaciones con: Gobiernos $\mathrm{Pa}$ tronos/Propietarios, Gobiernos Vendedores, Gobiernos Socios y Gobiernos Competidores.

\section{Palabras clave}

Relaciones externas, relaciones con 10 s gobiernos, gestión de la comunicación,

políticos enemigos

Key Words

External affaire, government relations, communication management, enemy politicians

\section{Abstract}

Since 1980 there have developed some strategies and programs of External Affairs and so nowadays they are conventional forms of corporate and institutional communication. The most problematic and contentious of these programs are those of External

Affairs Government Relations, discussed here. We met today with four scenarios that correspond to relations with: Government Employers / Owners, Sellers Governments, Partners and Competitors Governments Governments. 


\section{Introducción}

Esta última fórmula es hoy la dominante: sobre un único objetivo final que es el ciudadano, el que consume, vive, piensa o vota recaen todas las estrategias de quienes ofrecen marcas y productos diversos, ideas, actitudes y programas políticos. Sobre la definición de la agenda (sobre lo que deben percibir), sobre opciones y actitudes (lo que deben hacer), sobre la orientación del comportamiento (cómo debe actuar) y todo ello para llegar a determinar la deci- sión y la opción de compra y voto. Gobiernos y políticos compiten con agentes de consumo, ideológicos o de estilos de vida. Los gobernantes son competidores de todos los demás agentes sociales. Se analizan aquí los ámbitos en los que esta competencia político gubernamental intenta ser dominante: en la intromisión sobre el poder judicial, en la compra de expertise e inteligencia y en la presencia y control de los medios.

\section{Objetivos}

Presentar las últimas novedades en la actitud de las corporaciones e instituciones en su relación práctica con la administración, la clase política y los gobiernos.

\section{Metodología}

Análisis de casos. Experiencia profesional día a día en la planificación, estrategias y gestión de tales relaciones corporacionesgobiernos

\section{Principios de gestión de "Asuntos Externos" y Relaciones con los Gobiernos}

Una estrategia de relaciones con los gobiernos, como institución central y decisora de los Estados, se hizo imprescindible en la economía occidental a partir de las políticas de privatización de los años de 1980. Las políticas económicas intervencionistas que se establecieron en 1945 después del final de la segunda gran guerra, fueron eficaces durante tres décadas y establecieron en Occidente sistemas político-sociales de probada eficacia (socialdemocracia y neocapitalismo) con un desarrollo econó- 
mico y social superior a cualquier otra época de la historia en el cual las poblaciones tenían garantizados servicios básicos como seguridad, salud, educación, transporte, pensiones o jubilación.

A finales de los años de 1970 tiene lugar la primera crisis cíclica de alcance. Formalmente fue originada por el incremento de los precios del petróleo (fuente energética dominante) pero era de hecho una crisis de saturación en todos los órdenes, caracterizada por el acceso masivo (de toda la población) a los servicios referidos en ciudades aglomeradas. Dicha crisis define en realidad la incapacidad de los Estados socialdemócratas y neocapitalistas de atender a un nivel exigible la creciente demanda global de las poblaciones. No alcanzaba el dinero. Es la razón por la cual en los años de 1980 aquellos estados radicalmente intervencionistas directamente quiebran y desaparecen (fue el caso de los estados soviéticos), incapaces de gestionar la subsistencia física de sus poblaciones y aquellos estados moderadamente intervencionistas y planificados (los occidentales europeos sobre todo) tienen que llevar a cabo una reorganización de sus políticas de asistencia y de intervención en la economía. El gobierno del Presidente Reagan en los Usa inicia esta reorganización a partir de la publicación en 1981 de la "Desregulation Act" que da paso a una menor intervención del Estado en la economía de mercado y a las privatizaciones, especialmente en Europa, de aquellas industrias consideradas hasta entonces estratégicas como siderurgia, petróleo, carbón, construcción naval, transportes (ferrocarriles y aviones), militar, etc. El gobierno Thatcher en Gran Bretaña (conservador) y los gobiernos Mitterand en Francia, Craxi en Italia, Felipe Gonzalez en España, Schroeder en Alemania (todos ellos socialistas) tuvieron que llevar a cabo a lo largo de esa década de los ochenta un duro proceso de cierres y privatizaciones de empresas públicas para evitar fundamentalmente su quiebra y el peligro también de quiebra para el propio estado como sucedió en esos años en Rusia.

En esa situación en que los Estados consiguen fondos de parte de los compradores de los sectores económicos privatizados, las corporaciones (multinacionales o locales creadas con el fin de invertir en las industrias ofertadas) tuvieron que poner a punto una casi obligada y única estrategia. Vamos a verla con un ejemplo. Al romperse el monopolio del petróleo en un país europeo, deben crearse corporaciones que atiendan ese mercado, que son o bien creadas como empresas privadas o bien son multinacionales interesadas en participar de los hipotéticos beneficios que dicho mercado genera. En ambas situaciones sucede que corporaciones nuevas, desconocidas para los ciudadanos y usuarios, entran en un mercado y deben presentar o lanzar su marca, darse a conocer, posicionarse $y$ relacionarse con los gobiernos para los concursos públicos de privatización y con 
los mercados y consumidores para el desarrollo de sus redes comerciales.

En ese contexto nacen los programas de Asuntos Externos ("External Affaire") como herramientas de Relaciones Públicas y Comunicación que tienen el objetivo de cubrir estratégicamente esos tipos de relaciones con los gobiernos y con la sociedad y mercado. Aunque las formas básicas de gestión de los Asuntos Externos y de las Relaciones con el Gobierno llegan fundamentalmente de América del Norte, en muy buena medida se crean y consolidan en Europa Occidental y en los Países de la Unión Europea por ser en ellos donde el proceso de privatizaciones es mayor y tiene una importancia económica de mayor alcance.

Así pues, entre el año 1980 y la actualidad (2010) se han desarrollado estrategias, programas y paquetes de Asuntos Externos en modo que en la actualidad son ya formas convencionales de comunicación corporativa e institucional. Y en la actualidad, los más problemáticos, conflictivos y fronterizos de todos los programas de Asuntos Externos son los de Relaciones con los Gobiernos, razón por la que los analizamos y atendemos en este breve curso dedicado al Comunication Management y a las fronteras y perspectivas del mismo.

Naturalmente, una estrategia corporativa de relaciones con la Administración y los Gobiernos está directamente supeditada a la situación y estadio de evolución de los mismos. Desde la perspectiva de las rela- ciones y basándome sobre todo en la experiencia de sociedades y empresas que he tenido la oportunidad de conocer durante los últimos treinta años, encontramos cuatro situaciones que se corresponden con lo que definimos como:

- Gobiernos Patronos y Propietarios

- Gobiernos Vendedores

- Gobiernos Socios

- Gobiernos Competidores

La denominación se corresponde con la posición que las diferentes administraciones públicas han atravesado en Occidente desde 1980 hasta hoy pero equivalen igualmente a situaciones concretas de Gobiernos y Estados en diferentes partes del mundo o, con los procesos de regionalización de los Estados Europeos, con situaciones concretas de gobiernos regionales o locales en diferentes países. Los procesos no son necesariamente lineales. Existen Estados con un recorrido contrario a las privatizaciones (Venezuela por ejemplo) y regiones en Europa (Andalucía por ejemplo) en las que los Gobiernos locales han reorganizado una economía intervencionista en contraposición abierta con la tendencia general.

Veamos una presentación elemental de los diferentes tipos de Administración, Estado y Gobiernos desde esta perspectiva de objetivo de estrategias y programas de relaciones públicas y comunicación: 


\subsection{Gobierno Patrón y Propietario}

Se corresponde con aquel territorio en la cual el Estado o Gobierno es propietario directo o indirecto (a través de sociedad participadas) o es fuertemente intervencionista en la mayoría o en una buena parte de los sectores considerados convencionalmente como estratégicos en economía (agraria, alimentación, distribución, industrias como las telecomunicaciones, ferrocarriles, naval, farmacia etc.) o servicios (seguridad, salud, educación, medios de comunicación, etc.). El comportamiento de los gobiernos con la sociedad, ciudadanos y mercados es de corte colonial: los gobernantes se sienten administradores y responsables a largo plazo de bienes públicos y suelen carecer de la sensación de ser controlados al no existir organismos políticos con poder para vigilar y contrapesar su poder. Por ello, las relaciones con los Gobiernos se desarrollan en esa situación compleja (en nuestros programas las definimos como "Método Lawrence de Arabia”) a través de la creación de relaciones personales y de confianza. La clave estratégica está en situarse con absoluta seguridad en los escalones de la pirámide del poder, mejor mientras más cerca de los puntos de decisión. No suelen ser situaciones cómodas ni agradables para un trabajo profesional y suelen estar muy sometidas a las veleidades del decisor.

\subsection{Gobierno Vendedor}

Se trata de la situación vivida en los años de 1980 cuando los Estados Occidentales establecieron políticos neoliberales de menor intervencionismo y control de la actividad económica y de privatizaciones. Se trataba de reducir el riesgo de quiebra del propio Estado, de pasar a la iniciativa privada la responsabilidad de gestión sobre enteros sectores económicos estratégicos y de conseguir fondos y dinero para atender a los compromisos sociales que tales Estados habían adquirido con sus ciudadanos en cuanto a servicios y prestaciones sociales durante las décadas anteriores. Los Estados dejaron de ser dueños de industrias y desarrollaron y potenciaron sistemas mixtos públicos-privados en la prestación de servicios (educación, salud, seguridad, transporte, etc.). Muchos sectores económicos y de servicios pasaron de ser monopolios estatales a ser oligopolios con el sector controlado por un reducido número de corporaciones privadas o participadas por el propio Estado.

Para esa situación de privatizaciones y mezcla de lo público con lo privado nació en los ochenta un modelo de comunicación que hoy es convencional y regido por el sentido común. Una corporación necesitaba: 1. ser conocida por la entidad pública que iniciaba un proceso privatizador; 2. estar informada sobre el proceso; 3. tener acceso y ser reconocida como interlocutor; 4. contar con una marca que generase 
confianza y aceptación; 5. tener capacidad negociadora; 6. lanzar su marca al mercado para buscar apoyo entre prescriptores (medios de comunicación, expertos); 7. conseguir notoriedad pública, ser conocida por los potenciales usuarios y el mercado; 8. labrarse un prestigio y una reputación como marca comercial y para sus productos o servicios; 9. prepararse para conseguir redes de distribución, puntos de venta y clientes., etc. Respondiendo a esas necesidades se aplican programas hoy muy comunes de los que recogemos los más conocidos a continuación: 1. de inteligencia, análisis y conocimiento de la legislación, proceso privatizador, sector en oferta, entidades y personajes implicados en ello, etc. ; 2. de presentación y lanzamiento de la marca al mercado; 3. de relaciones públicas con los organismos y personas del gobierno y la administración responsables e implicadas; 4. de lanzamiento de la marca; 5. de notoriedad de marca y productos; 5 . de relaciones con los medios y prescriptores, intermediarios y creadores de opinión; 6.de posicionamiento y nicho; 7. de reputación. Etc.

Los programas de comunicación desarrollados como programas de relaciones con este tipo de administraciones y gobiernos se corresponden con los programas clásicos de los años ochenta y, como ya hemos dicho, forman parte del paquete convencional de la comunicación corporativa.

\subsection{Gobierno Socio}

Las privatizaciones de los ochenta impusieron obligaciones y compromisos tanto a los Gobiernos como a las Corporaciones que ocuparon los oligopolios sectoriales. Entre ellas y por ejemplo el de la Responsabilidad Social o el de Servicio Público. Y es desde esta perspectiva que se produjo una situación en la que Gobiernos y Corporaciones tuvieron que operar como "socios" en compromisos de diferente carácter.

El Estado y el Gobierno tiene, obviamente, responsabilidades de diverso orden ineludibles para con los ciudadanos. En cuanto interesa a nuestro discurso el Estado tiene al menos tres tipos de responsabilidades. Tiene responsabilidades económico-fiscales de regulación, de impuestos, de control y vigilancia, de presupuestos, de ayudas, de medioambiente y similares. Tiene responsabilidades socio-laborales de protección social, de jubilación y desempleo, de regulación del mercado laboral, de apoyo a organizaciones sociales y sindicales. Tiene responsabilidades políticas de educación, de información, de organización y motivación social, de protección del ciudadano y del mercado, de defensa del consumidor.

Las Corporaciones a lo largo de la década de los noventa desarrollaron programas de colaboración y partenariado con muchas de esas obligaciones del Estado. Manteniendo los formatos elaborados ya en la década anterior y desarrollando nuevas herramientas y estrategias. Las más importantes han 
tenido que ver con el Patrocinio para la formación ciudadana en defensa, por ejemplo, de la naturaleza y del medioambiente o de formación vial, o de formación económica y bancaria o en el uso de la energía o en la prevención sanitaria o en el fomento del deporte; en segundo lugar han tenido que ver con la Responsabilidad Social y el apoyo a iniciativas ciudadanas o al fomento del arte y de la cultura; en tercer lugar con programas de acción y apoyo social, generalmente a través de ONGs (Organizaciones no Gubernamentales) relacionadas con la solidaridad, la infancia, la vejez y los grupos sociales más desamparados. Esa colaboración entre Corporaciones y Gobiernos ha venido funcionando de modo regular hasta nuestros días.

\section{Gobierno competidor y enemigo}

Se trata de la situación más innovadora y reciente y la que preocupa a los responsables de Comunicación Corporativa en la actualidad. La posición de los Gobiernos comenzó a cambiar de modo importante a partir más o menos de la crisis menor de 2001/2003 y se ha afianzado ese cambio con la crisis de gran calado iniciada a finales de 2007 y en la que nos encontramos. Vamos a intentar analizar la nueva situación y comprender sus causas y posibles consecuencias.

La cuestión tiene que ver en un primer estadio o fase con la realidad del Poder Diluido $^{\mathrm{ii}}$, con la lucha por el espacio público, la competencia por definir y marcar la agenda pública y el interés por el mercado de la opinión y la definición de los comportamientos y actitudes de los individuos y del mercado. La mayor parte de nuestras sociedades avanzadas viven de la oferta de servicios. En esta oferta de servicios colaboran pero también concurren y a veces compiten la esfera pública y la esfera priva- da. Por ejemplo en servicios de seguridad o de educación o de salud: los ciudadanos en la mayoría de nuestros países tienen la opción de recurrir a una enseñanza privada, a una salud privada, a empresas de seguridad privada y lo hacen cuando consideran que la oferta pública no satisface sus necesidades y cuando pueden pagar tales servicios privados. Una situación similar aunque no tan clara se produce en oferta de servicios entre sectores comerciales y económicos que compiten entre sí: por ejemplo, una red de grandes superficies (hipermercados) puede actuar en realidad como un grupo financiero puesto que, alquilando espacio y soporte logístico a marcas comerciales, ofrece a los clientes servicios de financiación, servicios de instalación y mantenimiento, atenciones post venta, etc., utilizando como herramienta básica una tarjeta de fidelización que opera como dinero electrónico; su negocio es un negocio financiero compitiendo con la banca. Otra situación homóloga tiene lugar en la 
competencia por definir las actitudes y el comportamiento: buena parte de las grandes marcas comerciales ofrecen estilos de vida más que productos e intentan orientar el consumo hacia comportamientos que lo mantenga y fidelicen. Consumir agua en lugar de vino o cerveza, consumir tabaco o no consumirlo, alimentarse de una u otra forma, vestirse de una $\mathrm{u}$ otro manera, viajar "low cost", utilizar herramientas de una cierta tecnología (Apple en lugar de Microsoft), supone enfocar no solo el consumo sino la vida en una $\mathrm{u}$ otra manera. $\mathrm{Y}$ en ese enfoque de las costumbres está implicado todo, las creencias, los estilos de pensamiento, el consumo, las ideas políticas y el voto, la posición ante la vida en su conjunto.

En consecuencia, sobre un único objetivo final que es el ciudadano, el que consume, vive, piensa o vota recaen todas las estrategias de quienes ofrecen marcas y productos diversos, ideas, actitudes y programas políticos. Sobre el mismo individuo actúan con instrumentos de comunicación similares quienes piden consumir y quienes piden votar, buscando todos influir en modo determinante sobre sus decisiones de compra y voto y actuando para ese fin sobre la definición de la agenda (sobre lo que deben percibir), sobre opciones y actitudes (lo que deben hacer), sobre la orientación del comportamiento (cómo debe actuar) y todo ello para llegar a determinar la decisión y la opción de compra y voto.
Esa competencia en formas de acción social, detectada en los noventa y latente desde la crisis de 2003, ha explotado en una segunda fase con la crisis iniciada en 2007 y la necesidad, por una parte, de mantenerse en el mercado (no desaparecer) $\mathrm{y}$, por otra, de no aparecer como responsables o culpables de los nuevos "tiempos difíciles" (Arendt). El factor de actuación de todos los agentes sociales referidos se centra en la responsabilidad de lo negativo y en la huida de implicaciones. Se trata de situar, dentro de la agenda y de la opinión, la culpabilidad en el territorio de otros: por eso nadie acepta la responsabilidad sobre la crisis económica, nadie debía haberla previsto, nadie debía haber tomado precauciones y medidas correctoras y la opinión viene culpando a los especuladores en bolsa, a los economistas, a los empresarios, a los sindicatos y un poco a los políticos, según se va moviendo la aguja de la opinión ${ }^{\mathrm{iii}}$. Son situaciones de cada día. Por ejemplo, cuando el invierno último (2009/10) causa problemas en las redes eléctricas y poblaciones enteras quedan sin energía durante una semana, se produce un curioso espectáculo ante la opinión: los políticos culpan a las empresas eléctricas, éstas culpan a las autoridades que, bajo presión de los ecologistas, no permitieron modernizar las instalaciones, éstos no se dan por aludidos o derivan la responsabilidad hacia los inmobiliarios que han construido sin mesura ni planificación, etc. Lo mismo sucede cuando el problema lo cau- 
san los ferrocarriles, o el viento, o cuando la justicia descubre evasión fiscal o falsedad en balances y robo de dinero... Nadie es culpable. Todos "diluyen” la responsabilidad. Y, en consecuencia, todos son "enemigos" de todos. Los Gobiernos, para no perder índice en la intención de voto, culpan a otros agentes, quienes a su vez, culpan a otros, incluidos los gobiernos. Los Gobiernos son vistos por ello como "enemigos". Y la estrategia de comunicación en "Asuntos Externos" y en relaciones con los Gobiernos debe ser una Estrategia para convivir con "enemigos" y competidores. Esta es la actual situación y una de las más duras fronteras de evolución del "Communication Management”.

Para entenderla y definirla tenemos que intentar analizar cómo se ha llegado hasta aquí, hasta esta situación de responsabilidad diluida y de creación de confrontación entre los diferentes agentes sociales.

Desde un punto de vista corporativo y empresarial, los políticos "se han alejado de sus obligaciones para con la sociedad y el entorno" ${ }^{\text {,iv }}$. Por eso las Relaciones Externas, que hasta hace pocos años contaban con los representantes institucionales y políticos como parte permanente en las representaciones públicas, huyen de ellos: no tienen interés en que les resten protagonismo o, peor, en que los presenten como contrarios. Tampoco quieren verse contagiados por la imagen pública de los políticos. Es lugar común que esta imagen pública, la reputación de los políticos en la opinión pública occidental, es pésima. Suelen ocupar el último lugar en las encuestas de credibilidad y suelen situarse con frecuencia entre las primeras preocupaciones de los ciudadanos, contribuyentes y votantes ${ }^{\mathrm{v}}$.

Traducidas estas preocupaciones al entorno empresarial y corporativo, ¿cómo se contempla a los políticos?. ¿Qué posiciones deben adoptar los empresarios o los responsables máximos de las diferentes entidades económicas y sociales ante la clase política, los gobiernos e incluso las administraciones públicas?. La respuesta es de una creciente inseguridad y desconfianza. Lo más útil para la buena gestión de una corporación es no fiarse de las instituciones políticas y mantenerse al margen de ellas en todo lo que sea posible. No son fiables. Y esa desconfianza se fundamente en tres inseguridades básicas que afectan a la esencia misma del sistema político liberal y democrático. Son las siguientes.

\subsection{Inseguridad Jurídica como consecuencia del intervencionismo de los Partidos $y$ de otros poderes del Estado en el funcionamiento de la Magistratura}

Los políticos contemporáneos han decidido acabar y enterrar a Montesquieu y la separación de poderes para dar la victoria a un 
mito de "malditismo" encarnado en Maquiavelo, como referente de los principios de la gestión política y del gobierno. La actual situación que vivimos de "democracia mediática” de la televisión, la del poder diluido, la de los “doctores spin", la política y la comunicación basura son el epígono, la degeneración final y definitiva del modelo político liberal.

En torno a 1860 escribió Maurice Joly el conocido "Diálogo en los Infiernos entre Maquiavelo y Montesquieu" ". Lo hizo contra Napoleón III, el mismo emperador francés contra el que Carlos Marx escribió "El dieciocho Brumario de Luis Bonaparte". Para Marx el emperador es una pieza más de un tejido histórico resultante de la colaboración y alianza previsibles de las distintas lanzaderas del sistema productivo y liberal con un poder sometido a las fuerzas e intereses económicos. Para Joly el emperador ejemplariza el poder absoluto con los ropajes de la democracia de Montesquieu, el poder político por excelencia al que la sociedad se somete y del que la economía es, como los medios de comunicación, una herramienta de tiranía. En dicho "Dialogo" le toca a Maquiavelo, que probablemente había tenido tiempo en el Infierno de leer a Hobbes, el papel de malo, de estratega del exterminio democrático de la democracia mientras a Montesquieu le toca el papel de bueno, de defensor de la moral social (probablemente había meditado en el Infierno sobre Rousseau y Diderot) ${ }^{\text {vii }}$. Con absoluta clarividencia Joly dedica los diálogos undé- cimo y duodécimo a la prensa y su utilización en las funciones que Maquiavelo y Montesquieu proponen. Es uno de las mejores interpretaciones en mi opinión de la función de los medios de comunicación dentro del sistema y de los estados liberales. Pero el libro de Joly es un panfleto propagandístico en que da a su emperador "patadas en el trasero" del sufrido Maquiavelo. Porque la prensa y la propaganda, apoyadas en la imprenta, no eran cosa del siglo XIX. Fueron desde el Renacimiento y hasta los finales del siglo XX las herramientas preferentes en el ejercicio político del control social, de la motivación colectiva y de la justificación del poder ${ }^{\text {viii }}$. Fueron inseparables y utilizadas sin descanso por iglesias, monarquías, repúblicas, liberales, socialistas, dictadores y políticos de toda condición $^{\text {ix }}$. Pero ese largo ciclo de los medios de comunicación y de la propaganda como herramientas preferentes del poder político está cerrando con el siglo XXI y con ello se termina por imponer, contra Montesquieu, una visión "maldita" de Maquiavelo.

Siempre desde la perspectiva de un pensamiento mediático, el "cinquecento" y el Renacimiento en su conjunto tuvieron que resolver, fueron atormentados, por un básico problema social, el de la pérdida de confianza en las instituciones que soportaron los siglos pasados, el de la pérdida de credibilidad de la Iglesia Católica de su tiempo, la pérdida de confianza de los individuos en el sistema teocrático por ella 
establecido y de enorme utilidad durante los anteriores siglos en la reorganización y recuperación de Europa. Los grandes titanes del Renacimiento se vieron obligados a buscar certezas y referencias nuevas. Las encontraron por un lado en el Humanismo (Erasmo, Moro, Croce, Maquiavelo,..) y en el propio individuo, aquel creado por Dios como criatura propia, distinto y superior a toda la naturaleza, descrito por Pico della Mirandola (“De Hominis Dignitate”) en una forma que conmueve y emocionará para siempre ${ }^{\mathrm{xi}}$. Las encontraron por otro lado rompiendo la vieja Iglesia Romana con la Reforma Protestante y la Contrarreforma Católica, y buscaron sobre todo nuevas certezas y referencias en la Ciencia, en un lenguaje nuevo, no teológico, matemático, en el descubrimiento de las leyes de la naturaleza, de lo que significan el tiempo, el espacio y el movimiento ${ }^{x i i}$. Dentro de esa corriente y mientras Galileo, por ejemplo, buscaba la formulación de las leyes físicas del Universo, Maquiavelo trató y buscó las leyes naturales del Poder Político y como humanista reflejó en torno a un modelo humano (El Príncipe) el nuevo referente de credibilidad, estabilidad y organización de ese poder. El Príncipe es un mito universal como Ulises o Aquiles. Como mito El Príncipe no pertenece al pasado sino al futuro, no es un modelo sino un referente, no es un resultado causal de una evolución concreta sino un reflejo final hacia el que los hombres (en este caso los hombres de gobierno y los políticos) deben guiar su comportamiento, un espejo de valores y virtudes renacentistas que personifican en sí mismos y en su comportamiento el bien común, la supervivencia del reino y de la sociedad que le es propia. Como referente renacentista es moral y es racional y cuenta por ello con factores considerados más tarde como "negativos": ¿no era la astucia una cualidad clásica, cantada por Homero como propia de Ulises y de los Dioses? ¿No sucede lo mismo con el valor, la inteligencia, la capacidad de riesgo, la aplicación sin piedad de la ley? ¿No es el Príncipe de Maquiavelo una síntesis de algunos de los más decididos valores del clasicismo, es decir, de las costumbres de los antiguos, es decir, de las "mores maiorum", tradiciones o "moral"? Maquiavelo diseñó un modelo de poder y de organización de la sociedad sobre los principios del humanismo del siglo XV. Ese modelo se formulaba en torno a valores clásicos occidentales que se personificaban en el Príncipe, en quien la gente confiaba. Esa confianza en los Príncipes se ha mantenido durante siglos y ha comenzado a degenerar -según Tocqueville anunció- a medida que las democracias liberales y parlamentarias evolucionaron hacia el sufragio universal, hacia la dependencia de los votos de las masas. Por eso estamos en un fin de época. La "democracia mediática" de la televisión, la del poder diluido, la de los "doctores spin”, la política y la comunicación basura son el epígono, la degeneración final y definitiva del sistema político nacido en los 
orígenes de la Edad Moderna y culminante en los Estados liberales. Son la muerte no sólo de Montesquieu sino también del propio Maquiavelo.

\subsection{Inseguridad \\ Moral como consecuencia de} la dejación de funciones, buscando justificación $y$ credibilidad en agentes externos e inteligencia pagada

La razón última de esta inseguridad moral la predijo igualmente Tocqueville que proponía el "interés bien entendido" (el "bien común”) como objetivo prioritario de la política, del "buen gobierno" y anunciaba el mayor peligro de la democracia en el sometimiento de la acción política a los “instintos" viscerales de las mayorías ${ }^{\mathrm{xii}}$. Con ayuda de los periódicos, insiste Tocqueville, una democracia puede alcanzar cotas excelsas o derivar a los excesos morales más despreciables ${ }^{\text {xiv }}$. El voto universal estableció el factor mercado y el marketing en la política con la pantalla de la televisión y el espectáculo como herramientas y técnicas de mercado dominante y con los "malos modos" llamados "maquiavélicos" (engaño, confusión, mentira, desinformación...) a que antes hemos hecho referencia como estrategia dominante. Con la necesidad de conseguir votos masivos como objeto, las televisiones como herramienta y las prácticas citadas como estrategia, los políticos se han olvidado del "bien común" y de la gestión de los intereses públicos para concentrarse en ser agentes electorales que actúan preferentemente en la televisión, pasan a dedicarse a redactar comunicados de prensa y a ser actores televisivos según opinión reciente del propio Tony Blair $^{\mathrm{xv}}$. En esa situación, la opinión y el respeto que, como profesionales del interés público, reciben los políticos está bajo mínimos. Su credibilidad ha tocado fondo y la opinión pública les sitúa como la profesión con menos prestigio de todas las existentes.

En esa lógica hemos vivido en los últimos 20 años la aparición de sistemas estelares de profesionales en torno a la política. Al ser conocedores y conscientes de su situación los políticos, sobre todo aquellos que tienen responsabilidades ejecutivas de gobierno, necesitan recurrir a fuentes externas de credibilidad que justifiquen sus acciones, que den argumentos y causa a sus posibles errores $\mathrm{y}$, sobre todo, que den seguridad psicológica y personal a sus decisiones. Esos "seguros" y "reaseguros" que garantizan, explican y hacen presentables ante la opinión lo que los políticos deciden y ejecutan han consolidado tres categorías de profesionales:

- los grandes consultores internacionales que justifican las estrategias

- las grandes marcas de tecnología, de la información y la comunicación sobre todo, quienes con su responsabilidad 
sobre las redes, por ejemplo, justifican los errores inexplicables

- los magistrados que justifican las decisiones.

Los grandes consultores que justifican sus estrategias son predominantemente "spin doctors". La Sociedad Mediática ha sido el culmen, la última cima, de la Sociedad de Masas. En las décadas entre los 60 y 80 del siglo XX se generalizaron en Occidente la televisión, el consumo masivo, el ocio masivo (deporte, cine, seriales televisivos, "talk shows") y unos comportamientos colectivos que se corresponden con las leyes más amorales del comportamiento masivo, principios amorales que suponen la desaparición, enterrados por la zafiedad y la ignorancia ("toscos e ignorantes" decía Tocqueville) el hundimiento de los valores clásicos de occidente, aquellos recogidos entre otros por El Príncipe de Maquiavelo. Esta sociedad mediática es definida en un proceso de fin de época y desde la perspectiva de la televisión y los medios como "sociedad diluida" (Timoteo) o análogamente, "difusa" (T.Friedmann), "blanda" (Nye), "participada” (Minc), "líquida" (Bauman), etc. ${ }^{\text {xi }}$. Reúne muchas de las características de los grandes cambios de época en Occidente, del final de la era romana o del final de la era absoluta y moderna. El capitalismo moderno y la sociedad de nuestros días con él han llegado a ser un juego de espejos en el que no es posible distinguir la realidad de sus imágenes (George Soros). No se sabe si es "el perro que mueve la cola" o "la cola que mueve al perro", para utilizar el título de la primera película sobre los "spin doctors" de mediados de los 90' ("Wag the Dog”, de Barry Levinson, 1997, con Dustin Hoffman y Robert de Niro). Un capitalismo y una sociedad hechos de signos más que de riqueza y de realidades. Son masivas las evidencias de cómo las gentes viven a caballo entre una realidad, una vida, convencional (física, material, mental) y otra realidad, otra vida, "virtual” (de ocio, espectáculo, ficción, "second life"). Las gentes se reparten el día entre sus necesidades "fisiológicas" (dormir, comer, trabajar, viajar, hablar, leer, por ejemplo) y una segunda vida paralela (mirar, jugar, "navegar”, estar “colgados”, en la red, por ejemplo), pendientes de pantallas que llevan a otros espacios vitales no tangibles. "Hablar buscando el aplauso, hablar diciendo aquello que la gente quiere oír, hablar siguiendo la dictadura de la opinión dominante es una especie de prostitución de la palabra y del alma. La castidad...es (también) no someterse a estos comportamiento, no buscar los aplausos, obedecer la verdad" (Benedicto XVI, 2006) $)^{\text {xvii }}$

Paralelos a los "spin doctors" que justifican las estrategias, las tecnologías de la información y la comunicación (TIC/ICT) justifican los errores y los magistrados al servicio de la política dan justificación de las decisiones. Los "Jueces Estrella" son la más popular de esas sustitutivas de la acción de los políticos. Rizzo/Stella ${ }^{\text {xiii }}$ dedican el 
capítulo 14 de "La Casta..." a "Una casta nel cuore della Casta" y tratan de aquellos magistrados que son requeridos por el poder ejecutivo para garantizar, evitar los "errores legales”, justificar con la credibilidad que dan los textos legales, las decisiones, sean éstas acertadas o erradas, de los políticos. Estos magistrados abandonan la magistratura buscando situaciones económicas y personales muy privilegiadas, creando una "clan" de privilegiados paralelo a la "casta" de los políticos. Pero no es el único caso. A la misma lógica corresponden el movimiento de "manos limpias" presente en todos los países de occidente, con jueces que entran y salen de la política -en realidad los gobiernos y cargos políticos están llenos de ellos- o que utilizan la política en su desarrollo profesional. Es conocido en España por ejemplo el caso de una Juez que ha llegado y reinaba en el Consejo del Poder Judicial a principios del 2000 habiendo llevado a cabo una única actuación profesional, caracterizada por ser fundamentalmente mediática, confusa y sin resolver, pero conocida por su activismo político y habiendo llegado naturalmente en las ternas que los partidos presentan al Consejo. No es un caso único sino más bien un modelo.

Como si con el decaer del siglo pasado y el nacimiento del actual siglo XXI hubiese sucedido igual que en otro radical cambio de época, el anunciado por Séneca en sus “Cartas”, el recogido por S. Agustín en sus "Confesiones" o por Marguerita Duras en su "Adriano", un tiempo en que, caducadas las viejas creencias del clasicismo grecorromano y antes de que el cristianismo se impusiese como sustituto, el hombre se encontró sólo en la historia y lo definitivo fue entonces la búsqueda ("quaerere"), la interiorización, la recuperación de los valores esenciales e individuales del propio hombre como núcleo esencial para la intelección del fracaso vivido y para el salto hacia delante, hacia una época que, a partir de los siglos IV y V, resulto ser muy dura, resultó una "edad de hierro", una larga noche medieval. Como si estuviese sucediendo lo mismo que a finales del siglo XVIII y se anunciasen unas nuevas revoluciones atlánticas. Hacia 1722 publicó Montesquieu sus "Cartas Persas" en las que presenta la identidad de una sociedad parisina frívola, galante, imprudente, teatral pero aún capaz de coraje, de generosidad, de franqueza, de un cierto sentido del honor, de "un arte aristocrático de vivir". Hacia 1760 publica Rousseau su "Nouvelle Eloïse" en la que denuncia la impostura, la falsedad, la voluntad de dominio de esa misma sociedad dirigente francesa y propone una utopía como salida al desastre que anuncia. Hacia 1782 otro discípulo de Montesquieu, menos conocido, Choderlos de Laclos, presenta "Las Relaciones Peligrosas", en la que, en torno al juego de una tragedia amorosa, presenta ya a los parisinos como la suma del libertinaje y la corrupción, la ruptura de toda moral y norma, una sociedad fatua, olvidada de sus 
principios y atenta sólo a las formas. Laclos les anuncia y desea una revolución que acabe con ellos porque los encuentra víctimas de un delirio de omnipotencia que sólo se puede identificar con un incontrolado anhelo de autodestrucción, prepotentes de una pretendida nueva moral del placer orientada a exaltar la autonomía del individuo pero al servicio de hecho de un decidido proyecto despótico: para los protagonistas de esas relaciones peligrosas, Valmont y la marquesa de Merteuil, el juego de amor libre no tiene que ver tanto con el sexo como con el ejercicio incondicional de una perversa voluntad de dominio y una decidida voluntad de autodestrucción y muerte. La Revolución y la muerte no tardaron en llegar.

\subsection{Inseguridad} Mediática con el intervencionismo más descarado de

la clase política en los medios de comunicación $y$ preferentemente en las televisiones

En esa escala de reputación profesional por parte de la opinión pública que venimos citando y en la mayoría de las encuestas oficiales, los periodistas superan en prestigio a los políticos por muy poco: los políticos son los últimos y los periodistas los penúltimos. La perdida de credibilidad del actual periodismo es fundamentalmente debido a que con mucha frecuencia ejerce como "periodismo de convalidación" en el cual ha desaparecido la vieja objetividad (la "accuracy" o precisión de Pulitzer en The World, la objetividad "técnica”, soportada por dos fuentes fiables, de Ochs en el New York Times) a favor de la tendenciosidad y los prejuicios. La tendencia es conocida en los Usa como "Media Bias”. Ann Coulter ${ }^{\text {xix }}$ sostiene que esa distorsión es cosa de la izquierda. Eric Alterman ${ }^{\mathrm{xx}}$ acusa sin embargo a la derecha. Planel, ex director de Le Monde, de quien recogemos la expresión “periodismo de convalidación”, que se trata de una degradación del periodismo sometido, por razones de audiencia, a las exigencias cada día más decadentes de la misma y, por razones de financiación, sometido a los intereses de los grupos políticos y de las corporaciones dominantes. Se trata del manejo con que las "stories" o campañas propias del periodismo actual elaboran sus contenidos. Es la técnica "slanting". "Slanting" es el modo de construir una historia tendenciosa, el proceso de selección de detalles que favorecen o desfavorecen la línea argumental prefijada. Prejuicios, tendenciosidad, manipulación, construcción de una historia o noticia con objetivos ideológicos, económicos o políticos. Y todos haciendo lo mismo, causando una constante distorsión de la realidad y elaborando la sopa de comida basura que es la televisión y la tele realidad en nuestros días $^{x x i i}$. Los Media actúan como un agente económico más, operando sobre todo en su propia rentabilidad y beneficio. 
La estrategia de las corporaciones en sus relaciones con los medios ha cambiado por ese motivo de modo muy radical en los últimos pocos años, tal vez desde la penúltima crisis publicitaria y mediática (la conocida como de los "punto com") en 2003. Las organizaciones económicas sienten una absoluta desconfianza y un importante rechazo hacia los Medios de Comunicación de Masas y han definido estratégicamente una decidida preferencia por las relaciones directas con el público final. Las relaciones con los medios han sido tradicionalmente contempladas como una oportunidad, aunque arrancasen de una información negativa. Hoy son vistas como un problema porque, ¿quién se puede fiar “a priori” de los medios convencionales (prensa, radio, televisión) si todos tienen como finalidad declarada su propia cuenta de resultados, es decir, sólo son capaces de una intermediación interesada y en consecuencia cara?. La gente no consigue ya creer ni en la $\mathrm{BBC}^{\mathrm{x} x i i}$. Además es posible, utilizando los post-media, establecer relaciones directas con ese anhelado consumidor final sin necesidad de recurrir a las difíciles y caras televisiones generalistas. Los sistemas B2B ("business to business") y B2C ("business to consumer") como sistemas de conexión y compra, los usos de Internet para presentar catálogos y ofertas, para el comercio electrónico o para el descubrimiento de novedades, permiten una nueva estructura del organigrama económico y político. Los grandes grupos de medios convencionales comienzan a encontrarse con competidores a su medida: los grandes Operadores de red (las Telecom), por una parte, que salen con atractivas ofertas convergentes (telefonía, adsl, ocio, información...) ofrecidas por uno de los posibles sistemas red (cable, satélite, wifi...); los grandes Operadores de contenidos (Microsoft, Google, AOL, MySpace, Yahoo...), por otra parte, que están en condiciones de casi "saturar" la demanda a bajo coste; sin olvidar, en tercer lugar, las capacidades de los fabricantes de utillaje ni los gobiernos ansiosos por el control de la información sobre sus ciudadanos (con motivos públicos de seguridad) y sobre sus empresas (por motivos fiscales). Se abren amplias posibilidades de actuación alternativa a la convencional en ese panorama. Si sumamos a estos nuevos soportes básicos o nuevos "prescriptores", las posibilidades que el marketing está abriendo y las facilidades que el software posibilita del tipo de desarrollos de "back office”, gestión de la información, CRM / CSM, "call centers", "continous tracking”, etc., parece fácil prever buenos tiempos para el "below the line" y los "postmedia" y dificultades para todo lo convencional que no se renueve. Es así posible el viejo sueño de la fidelización directa del usuario "amigo/socio para toda la vida”. Son de nuevo y aquí otras tecnologías, la de Gestión Documental y de Bases de Datos, las CSM y CRM, quienes posibilitan el tratamiento individual de los clientes, la segmentación en minitargets, los usos de microcomuni- 
cación, el incremento del "cross-selling" y del "up-selling", el conocimiento de las cifras reales de rentabilidad de cada cliente y de las ventajas de premiar y negociar sus partidas, el pensamiento de un "cliente para toda la vida” unido a la calidad acordada y al bajo precio.

\section{Estrategias $y$ herramientas de gestión de las relaciones con "gobiernos enemigos"}

Contamos para esta difícil situación actual con estrategias y herramientas de gestión de la Comunicación bastante bien definidas y experimentadas. Definen las preocupaciones actuales de los Dircom y son las siguientes:

- Gestión de Intangibles

- Gestión de la Reputación

- Gestión actualizada de las Crisis

- Gestión de la Responsabilidad Social de las Empresas

- Gestión de "Think Tank" y de "Lobbies"

Las tres primeras (Intangibles, Reputación y Crisis) son sobradamente conocidas entre los profesionales. La Gestión y uso de los "Think Tank" y de los "Lobbies" nos obligaría a ir más allá de este artículo de amplitud limitada. Se trata de técnicas que necesitan de una mayor especialización ${ }^{\text {xxiv }}$.

La Responsabilidad Social de las Empresas es un programa y propuesta de enorme interés para el futuro del sistema económico. La crisis que estalló a caballo entre
2007 y 2008 tiene, entre otras, tres lecturas de aceptación bastante común ${ }^{\mathrm{xxv}}$ :

1. Ha dejado al descubierto la insuficiente defensa de las condiciones de vida de los estratos sociales inferiores, formados ahora no tanto por obreros de fábrica sino por un ejercito de trabajadores de servicios dependientes con bajos ingresos, mileuristas y trabajadores en paro de cualquier procedencia. Se les pide a estos estratos castigados por la crisis encontrar un camino que no consiguen encontrar en el mundo de la iniciativa privada individual (autónomos) dentro de un desarrollo estancado y con características de gran depresión.

2. Ha dejado al descubierto una perversión que se ha consolidado en los últimos 20 años, consistente en que las grandes corporaciones, los plutócratas, han llevado a cabo un asalto al estado convirtiendo el poder público en un poder diluido, haciendo imprescindible un restablecimiento de reglas de juego por parte de tales poderes públicos que 
sean capaces de crear una red de protección a favor de los estratos sociales víctimas de la situación y que pueda ser permanente un nivel social de bienestar al alcance de todos o de la inmensa mayoría.

3. Ha dejado al descubierto la incapacidad de la socialdemocracia más avanzada (la “tercera vía”) y del capitalismo más avanzado (el turbocapitalismo), porque los socialdemócratas (liderados por Blair y Schroeder) intentaron, para cabalgar el nuevo y potente capitalismo global, desmontar, desde mediados de los noventa, las instituciones que soportaban el "welfare".

La conclusión a esta reconocida situación tiene al menos dos alternativas. Una bastante común a las organizaciones que se definen de izquierdas (el conocido periodista inglés Timothy Gaston Ash está haciendo una campaña promotora) auspicia la vuelta a una versión modernizada de la "economía social de mercado" que se debe fundamentar en la creación por parte del Estado de una poderosa estructura jurídica y normativa para las empresas privadas y de otra poderosa estructura paralela de organismos autorreguladores de la libertad, la competencia y los mercados.

Otra segunda alternativa, que sin renegar parcialmente de la anterior tiene muchas mayores perspectivas y futuro, consiste en la potenciación y apoyo de un nuevo tipo de capitalismo social definido como "em- presa social" o de "responsabilidad social de las empresas RSE".

Este concepto y fórmula de RSE va mucho más allá de la "Responsabilidad Social Corporativa RSC", programa estrella de las corporaciones en la última década, que ha terminado por ser un programa de marketing promocional de las instituciones. Se trata de un nuevo tipo de empresa y de capitalismo fundamentado sobre los siguientes principios:

1. Aceptando el beneficio como principio básico, irrenunciable y primero también del nuevo capitalismo

2. En los últimos 20 años y en el turbocapitalismo, ese beneficio entendido como resultado y rentabilidad a corto plazo, ha sido el objetivo casi exclusivo de todo el funcionamiento del sistema

3. La crisis ha roto con esa feroz lógica del corto plazo o beneficio inmediato y está potenciado y resaltando estilos de vida muy contrarios, definidos por una mayor ascesis, por concepciones "low cost”, por la intelección de la vida con factores esenciales relacionados con la ecología y el medioambiente, el ahorro energético, el uso cuidadoso del agua y de las materias primas, el mantenimiento inalterable de derechos adquiridos e irrenunciables como la salud universal, la educación gratuita y para todos, la seguridad garantizada por el Estado, el cuidado de los más débiles (ancianos, niños, enfermos...). 
4. Todo ello significa que el capitalismo que viene sólo podrá alcanzar beneficios si cumple un segundo principio básico, como adherente premisa al primero, al del beneficio, que es el de responder a una rentabilidad social manifiesta, contablemente medida y reconocida por los usuarios y el mercado. Solo si es ecológico, sólo si produce con materiales y formas que no generen daño social (en salud, en seguridad....), sólo si propone productos y servicios de calidad aceptable y ofrecida a un precio competitivo y por ello socialmente estimable, sólo si se preocupa de que su oferta sea socialmente aceptada, sólo en esas condiciones conseguirá su primer objetivo, el del beneficio. Se trata de un salto cualitativo en relación con la Responsabilidad Social Corporativa, que, a pesar de sus excelentes intenciones teóricas, se ha desarrollado fundamentalmente como un programa de marketing y promoción institucional.

5. Capitalismo social o empresa social será por tanto aquella que para lograr beneficio incluye como componente intrínseco factores de interés social manifiestos de múltiples formas: calidad, reputación, seguridad, formación, salud, comportamiento individual, cuidado del medioambiente, etc. Deben cumplir la condición de que tales factores de interés social útiles, visibles y susceptibles de ser contablemente medidos. Se trata en consecuencia de pro- yectos estratégicos, dirigimos desde el medio plazo más que del corto e inmediato beneficio.

En paralelismo con estos desarrollos, la Unión Europea y los diferentes estados nacionales están apoyando esta propuesta. En España ha sido creado el pasado 20 de enero de 2009 el CONSEJO ESTATAL DE RESPONSABILIDAD SOCIAL DE LAS EMPRESAS, que pretende desarrollar formas nuevas de colaboración entre los agentes sociales para responder a aquellos desafíos económicos, sociales y medioambientales que la crisis ha dejado a la intemperie $^{x x v i}$. En la misma perspectiva están teniendo lugar iniciativas públicas o privadas de interés como la creación de Redes de Territorios Socialmente Responsables (RETOS) que intenta llevar a esa responsabilidad social colaborando a las empresas, administraciones públicas, ciudadanía $\mathrm{y}$ agentes sociales o como la reciente propuesta y Ley de Ciudadanía Corporativa impulsada por las tres Consejerías Sociales de la Generalitat Valenciana (Inmigración y Ciudadanía, Bienestar Social y Comercio e Innovación).

Estas iniciativas y líneas de desarrollo tienen, sin embargo, un problema básico: la falta de claridad conceptual y de programas visibles y eficaces de aplicación de las mismas ${ }^{x x v i i}$. Con esta iniciativa puede suceder lo que ha pasado con el proyecto y mundialmente imitado programa de Tony Blair de las "Industrias Creativas". Después de 10 años de aplicación, el nuevo gobierno 
Brown ha descubierto que en realidad tales programas no han pasado de ser una propuesta de marketing, que ha tirado a la basura importantes cantidades de dinero del estado a favor de artistas, diseñadores, arquitectos creativos, moda, cine...etc., que nadie sigue, nadie entiende y nadie sabe para qué han sido financiados ${ }^{\mathrm{xxv} \text { iii }}$

Los programas de RSE son, desde esta perspectiva, un ámbito de extraordinario interés para los gestores de la Comunicación Corporativa. Los pone en condiciones de elaborar una doctrina, que, tal vez, pueda ser la doctrina de la "cuarta vía" socialdemócrata o tal vez el "nuevo capitalismo” por el que Sarkozy suspira.

Las posibilidades y responsabilidades de la Comunicación en la construcción de la Sociedad del Siglo XXI son, desde esta situación, extraordinarias. Porque tratándose de operar sobre cambios de percepciones, es decir, tratándose de gestionar un territorio de intangibles, de reputación, de imágenes sociales, de política y de ideas, la batalla definitiva se da en provocar el cambio de mentalidad y percepción en los propios agentes políticos. El problema está en la mentalidad de los actuales gestores públicos que es necesario transformar. Por eso, detrás de los modelos y herramientas que ya conocemos de gestión, es imprescindible actuar socialmente y en mi opinión, intentando recuperar la credibilidad, la reputación, ante todo, de la actual democracia o llevarla a un estadio superior similar al que se está buscando en los secto- res económicos más afianzados. Es necesario llevar a cabo en la Democracia Parlamentaria occidental un proceso equivalente al que se está llevando a cabo en muchos sectores económicos.

Por ejemplo, en el de la energía. La industria del Petróleo es claramente consciente de que su era está abocado a un pronto final - calculan unos 30/40 años de uso del petróleo como fuente energética dominante- y por ello ha definido ya hace tiempo y trabaja desarrollando energías alternativas, construyendo una nueva era más allá del petróleo ("beyond petroleum”). Como no se sabe con claridad cual pueda ser la fuente energética definitiva se experimenta con varias alternativas: solar, eólica, nuclear, hidrógeno, biocarburantes, etc. Las corporaciones energéticas no tienen aún clara la salida definitiva pero están en camino y en búsqueda de una salida. Una transición de similar calado está teniendo lugar en otros muchos sectores de la economía y de la vida en el mundo. La sanidad, por ejemplo, donde la tecnología por una parte y las investigaciones en genética o neurología por otra están transformando todo el proceso de atención sanitaria. La seguridad, por ejemplo, con cambios radicales en la función de las policías y los ejércitos. El transporte, la alimentación, el turismo.... todo está sufriendo un salto cualitativo a una dimensión nueva, menos el sistema político que se mantiene esencialmente en una estructura de democracia parlamenta- 
ria definida en el siglo XVIII y consolidada a lo largo del siglo XIX y XX.

En mi opinión y en el entorno que aquí tratamos, las herramientas de gestión de intangibles, de la reputación, de la crisis y sobre todo de la RSE pueden posibilitar la recuperación de la Democracia, pueden elaborar alternativas y salidas teóricas y prácticas a los tiempos oscuros que estamos viviendo.

\section{Conclusiones}

(Ver resumen)

\section{Referencias}

\section{BIBLIOGRÁFICAS}

ALTERMAN, E. (2003) What liberal media? The truth about bias and the news. New York, Edit. Basic Books.

ÁLVAREZ FERNÁNDEZ, J. T. (2005) Gestión del Poder Diluido. Madrid, Edit. Pearson.

ARENDT, H. (1983) Men in Dark Times. Nueva York, Edit. Harcourt Brace.

BAUMANN, Z. (2005) Liquid Life. Cambridge, Edit. Polity Press.

BERTA, G. (2009) Eclisse della socialdemocrazia. Milano, Edit. Il Mulino.

BOSETTI, G. (2001) Spin. Venezia, Edit. Marsilio.

CAMPBELL, A. (2001) The Blair Years. Extracts from the A.Campbell Diaries. London, Edit. Random House.

CASTELLS, M. (2009) Comunicación y Poder. Madrid, Edit. Alianza.

CASTORIADIS, C. (2010) Democratie et Relativisme. París, Edit. Mille.

COLOMBO, F. (1998) La cultura sottile. Milano, Edit. Bompiani.

COULTER, A. S. (2003) Liberal lies about the American Righ. New York, Edit. Three Rivers Press.

DILETTI, M. (2010) I think Tank: le fabbriche delle idee in America e in Europa Bologna, Edit. Il Mulino.
FLETCHER, A. (2007) Time, Space and Motion in the Age of Shakespeare. London, Edit. Harvard Univ.

Press.

GRAZIANO, G. (2002) Le Lobbies. Bari, Edit. Laterza.

JOLY,M. (1982) Diálogo en el Infierno entre Maquiavelo y Montesquieu. Barcelona, Edit. Muchnik, $2^{\mathrm{a}} \mathrm{Ed}$.

McGANN, J. (2007) Think Tanks and Policy Advice in the Us. New York, Edit. Routledge.

MINC, A. (1995) L'Ivresse democratique. París, Edit. Gallimard.

NYE, J.S. (2002) La paradoja del poder norteamericano. Madrid, Edit. Taurus.

PLANEL, E. (2005) Procès. París, Edit. Stock.

REVAULT, M. (2010) Pourquoi nous n'aimons pas la democratie. París, Edit. Seuil.

RICH, A. (2004) Tank, Public Policy and the Politics of Expertise. New Cork, Edit. Cambridge University Press.

RIZZO, S. y STELLA, G.A. (2007) La Casta: cosí i politici italiani sono diventati intoccabili. Milán, Edit. Rizzoli.

STONE, D. y DENHAM,A. (Editores) (2004) Think Tank traditions: Policy Research and the Politics of Ideas. Manchester, Edit. Manchester Univ. Press. 
TOCQUEVILLE,A. (2002) La democracia en América. México, Edit. FCE.

ZOLO, D. (1994) La democracia difícil. Madrid, Edit. Alianza.

\section{HEMEROGRAFICAS}

La Responsabilidad Social Corporativa en la encrucijada."Telos: Cuadernos de Comunicación e Innovación”, no 19 (abril-junio 2009), pp.50-143.
Staying ahead: the economic performance of the UK's Creative Industries. "Creative Britain. New Talents for the New Economy”, Febrero 2008, pp. 23-36.

\section{Cita de este artículo}

ÁLVAREZ FERNÁNDEZ, J. T. (2010) Los políticos como enemigos. Gestión de los "external affairs" y de las "government relations" Revista Icono14 [en línea] 1 de Julio de 2010, Año 8, Vol. 2. pp. 383-406. Recuperado (Fecha de acceso), de http://www.icono14.net

\section{NOTAS}

${ }^{\text {i }}$ Para una explicación de los cambios aquí referidos desde la perspectiva de los mercados y de la comunicación ver: BARBER,B.J., Con\$umed. How Markets corrupt Children, infantilize Adults and Swallow Citizens Whole, 2007. Consultada la traducción italiana: BARBER,B. J., Consumati. Da Cittadini a Clienti, Einaudi, Torino, 2010

ii TIMOTEO,J., Il Potere Diluido...o.c.cap.4; MINC,A., L'Ivresse democratique, Gallimard, Paris, 1995; NYE,J.S., La paradoja del poder norteamericano, Taurus, Madrid, 2002; ZOLO,D., La democracia difícil, Alianza,Madrid, 1994, BAUMANN, Z., Liquid Life, Polity Press, Cambridge, 2005; COLOMBO, F., La cultura sottile, Bompiani, Milano, 1998

iii CASTELLS,M., (ed.) Comunicación y Poder, Alianza, Madrid, 2009

iv ARENDT, H., Men in Dark Times, Harcourt Brace, Nueva York, 1983, pp.4-5: "La función de la esfera pública (de la política) consiste en dar luz sobre los asuntos humanos, ofreciendo un espacio en el que los hombres puedan mostrar, con hechos y palabras, aquello que son y aquello que pueden hacer, para el bien y para el mal. La oscuridad ha descendido cuando esta luz se ha eclipsado por una "carencia de credibilidad", por el "gobierno invisible" de un discurso que no clarifica sino que oculta, un gobierno de slogans morales y de otro género que, con el pretexto de presentar antiguas verdades, degradan cada una de éstas a una insignificante banalidad.... La esfera pública ha perdido aquella capacidad de iluminar que formaba parte de su naturaleza original. En occidente, donde la libertad política ha estado incluida, desde el fin del mundo antiguo, entre las libertades fundamentales, son cada día más numerosos aquellos que, utilizando esa misma libertad política, se alejan de sus obligaciones para con la sociedad y el entorno..... lo que se pierde es la mediación, personal e insustituible, que debe haber entre el individuo y sus semejantes"

v A modo de ejemplo: el CIS (Centro de Investigaciones Sociológicas), organismo oficial español de seguimiento de la opinión, recoge desde 1963 barómetros mensuales de opinión que gozan de buen prestigio. Preguntan entre otras cuestiones y en encuesta abierta sobre las preocupaciones inmediatas de los ciudadanos. A lo largo del 2009, aparece la "clase política" como preocupación inquietante oscilando entre los puestos 3 y 6 del ranking. Ven a los políticos como un problema nacional superado sólo en modo regular por el paro, el terrorismo y la vivienda. http: / / www.cis.es/cis/opencm/ES/2 barometros/depositados.jsp. 


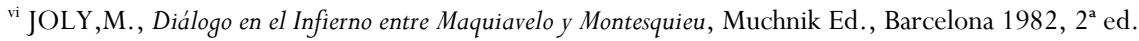

${ }^{\text {vii }}$ Fernando Savater en el Prólogo al libro de Joly citado.

viii Como es sabido, la prensa nació en el Renacimiento (Ludovico Ariosto presenta en “Orlando Furioso" a Pietro Aretino (1492-1556), ejemplo de renacentista inmortalizado por Tiziano, como su formal inventor). Apenas un par de siglos más tarde y en las guerras de religión entre Reforma y Contrarreforma nació la Propaganda (formulada como tal en el Concilio de Trento) como herramienta de motivación y control social. Ver TIMOTEO ALVAREZ,J., "Los medios y el desarrollo de la sociedad occidental” en BARRERA,C., (ed) Historia del Periodismo Universal, Ariel, Barcelona, 2004, pgs. 26ss.

ix TIMOTEO ALVAREZ,J., Historia y Modelos de Comunicación en el siglo XX, Ariel, Barcelona, 1987

${ }^{x}$ PICO DELla MIRANDOLA, G., De Hominis Dignitate. La Dignitá dell'Uomo, (Versión original con traducción de Carlo Carena), Silvio Berlusconi Ed., Milán 1997

xi "Dios dijo a Adán: a ti no te doy ni una apariencia concreta ni un aspecto particular ni una función especial para que tu crees y poseas tu propio lugar, tu propio aspecto y las funciones que por ti mismo elijas según tu deseo y juicio. Los demás seres tienen una naturaleza definida y cerrada según leyes por mí establecidas. Tu sin embargo, no limitado a ningún confín, determinarás tu propia naturaleza según tu libre albedrio. Te he colocado en el centro del universo para que desde allí tu puedas utilizar con facilidad todo lo que el universo contiene. No te he hecho ni celeste ni terreno, ni mortal ni inmortal, para que por ti mismo elijas la forma que prefieras como un libre y noble modelador y alfarero de ti mismo. Podrás degenerar hacia los seres inferiores y terminar siendo una bestia o podrás regenerarte hacia lo superior y terminar siendo un dios, según tu exclusivo juicio y decisión” . Oc. Pgs. 8-9 y 89-90 (la traducción a español es mía, JTA)

${ }^{\text {xii }}$ FLETCHER,A., Time, Space and Motion in the Age of Shakespeare, Harvard Univ. Press, Londres, 2007.

xiii “No temo decir que la doctrina del interés común bien entendido me parece la mejor de todas las teorías filosóficas, la más apropiada a los hombres de nuestro siglo y la más poderosa garantía que les quede contra ellos mismos....Si los ciudadanos, al hacerse iguales, permanecen toscos e ignorantes, es imposible prever hasta que exceso de estupidez podría llegar su egoísmo y no es fácil decir anticipadamente en qué vergonzosas miserias se sumergirían ellos mismos por el temor de sacrificar alguna parte de su comodidad al bienestar de sus semejantes" TOCQUEVILlE, A.de., La democracia en América, FCE, Mexico, 2002, pp.485-6.

xiv TOCQUEVILLE, A de, o.c., pp.477-480

${ }^{\mathrm{xv}}$ Así lo reconoce Tony Blair, en un discurso en Reuter de Londres (12 Junio 2007): “Our Nation's Future - Public Life": Afirma T.Blair: "Now these changes are better known to many of you than to me, and they are obvious. Less obvious is their effect. The news schedule is now 24 hours a day, 7 days a week, and it moves in real time. Papers don't give you up to date news - that is already out there - they have to break stories, try to lead the schedules, or they give a commentary. And it all happens with outstanding speed..... You have to respond to stories also in real time. Frequently the problem is as much assembling the facts as giving them. Make a mistake and you quickly transfer from drama into crisis...... And I am going to say something that few people in public life will say, but most know is absolutely true. A vast aspect of our jobs today, outside of the really major decisions, as big as anything else, is coping with the media, its sheer scale, weight and constant hyper-activity.... If you are a backbench MP today you learn to give a good press release first and a good parliamentary speech second”. En frase conocida de A.Campbell: “en la oposición hemos comprendido que la comunicación no es la guinda del pastel sino integrante (estratégico) de lo que hay que hacer. Es lo que hemos intentado aplicar en el gobierno" CAMPBELL,A., The Blair Years. Extracts from the A.Campbell Diaries, Random House, Londres, 2001

${ }^{\mathrm{xvi}}$ Ver referencias bibliográficas en nota 2 
xvii TIMOTEO AlvareZ, J., Gestión del Poder Diluido, Pearson, Madrid, 2005; CASTORIADIS, C, Democratie et Relativisme, Mille, Paris, 2010; BOSETTI,G., Spin, Marsilio ed. Venezia, 2001 ;

REVAULT,M., Pourquoi nous n'aimons pas la democratie, Seuil, Paris, 2010

xviii RIZZO,S., STELLA,G.A., La Casta: cosí i politici italiani sono diventati intoccabili, Rizzoli, Milán 2007, pgs. 184-192.

xix COULTER,A., Slander: Liberal lies about the American Righ. , Three Rivers Press New York $2003^{\text {xix }}$

xx ALTERMAN,E., What liberal media? The truth about bias and the news. Basic Books, New York 2003

${ }^{x x i}$ PLANEL,E., Procès, Ed. Stock, Paris, 2005

xxii CEFISO WP, Informe: "Political Polarization and the Electoral Ëffects of Media Bias". Agosto: 2006.

xxiii Encuesta de “The Guardian” con el Instituto ICM (Julio 2007): sólo en 22\% de los británicos confian en los informativos de la BBC. No les dan mayor credibilidad que a los informativos de Sky Channel.

${ }^{\text {xxiv }}$ Para una introducción a este tipo de téncinas, ver: RICH, A., Think Tank, Public Policy and the Politics of Expertise, Cambridge University Press, New Cork, 2004; McGANN, J., Think Tanks and Policy Advice in the Us., Routledge, New York, 2007; STONE,D., DENHAM,A. (eds), Think Tank traditions: Policy Research and the Politics of Ideas, Manchester Univ. Press, 2004. GRAZIANO,G., Le Lobbies, Laterza, Bari, 2002. DILETTI,M., I think Tank: le fabbriche delle idee in America e in Europa, Il Mulino, Bologna, 2010

${ }^{x x v}$ BERTA,G., Eclisse della socialdemocrazia, Il Mulino, Milano, 2009

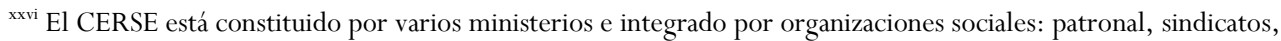
ongs y similares. Su cabeza visible es Juan Jose Barrera, director general de “Economía Social y RSE” del Ministerio de Trabajo

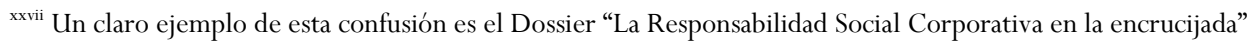
publicado por Telos:Cuadernos de Comunicación e Innovación, Fundación Telefónica, no 19 (abril-junio 2009), 50143.

xxvii The Work Foundation, "Staying ahead: the economic performance of the UK's Creative Industries”, Junio 2007; Minist. For Culture, Creative Industries and Tourism, "Creative Britain. New Talents for the New Economy", Febrero 2008 